\title{
Independence to Interdependence: A Much Harder Lesson to Learn?
}

Jennifer Lehmann and Rachael Sanders

Editors, Children Australia
"I'm going out and you can't stop me!" "I'll spend my money on whatever I like!" "I'll go out with whoever I want!" These are all statements we have heard from children and young people. We probably said the very same words to our own parents or carers. Adults so often interpret these statements as a reflection of rebellious and impossible behaviours at worst, or expression of a grab for independence at best ... or you might have reacted differently ... but did you? Western societies value the notion of independence, associating the concept with choice and competency, but also with freedom and rights. As parents and carers of young people we want them to grow to adulthood and be able to exercise agency in the world, but do we ever prepare them for the 'real' world - one of complex interdependency in which virtually every action, every choice, every consequence and even a sense of self depends on others?

It sounds trite to begin this conversation by reminding ourselves of our dependence on others for food to buy, electricity to cook it with, clean dishes to eat from and water in the tap for a subsequent cuppa. However, this is our reality and almost everything we do in our lives is made possible because of the interactions with, or the efforts of, someone else. Why, then, do we persist with this idea that we want our kids to grow up to be independent and what do we mean by this? Is it that we think we will be relieved of responsibility for their care, do we want to regain a sense of ourselves and private space, do we think that health and wellbeing is somehow enhanced by being independent, or does it mean that we can take pride in our parental abilities to get them there? And where do such beliefs come from - because most parents continue to care and support their children to their dying day and many children reciprocate as their parents become frail.

To be provocative, we're suggesting that this idea we hold of independence, which is inculcated in young people in myriad ways, is the reflection of a darker side of human relationships. It is anti-care and an abrogation of responsibility for others' wellbeing - and this has long been reflected in the withdrawal of services and support to young, 'looked after' children by government as they 'come of age'. In re- cent years, this state of affairs has been challenged and is changing (Mendes \& Moslehuddin, 2006; Osborn \& Bromfield, 2007), but our Western society still battles, somewhat ambivalently, with the business of independence and how to respond to those amongst us who are disadvantaged; those who need additional and ongoing supports for periods of their lives, and those who may need lifelong care and/or monitoring. On the one hand, we recognise the level of interdependence required for adequate care of those who are experiencing disability, but on the other, government policy reflects our concern that people stand on their 'own two feet' - 'the age of entitlement is over, and the age of personal responsibility has begun' (Kenny, 2014, para. 1) as we were recently told by Joe Hockey, Federal Treasurer, as he prepared us for budget [bad] news.
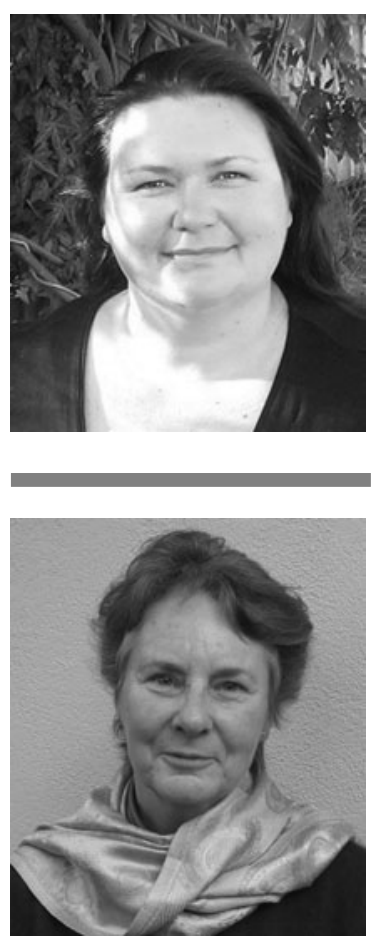
What does this all mean when it comes to raising and educating our children? Clearly, there are major implications if we raise them to believe that growing up equals independence. It reduces the sense of concern or responsibility towards others, it risks heightening a sense of separateness from others (and 'othering' behaviours) and it allows for easy dismissal of policies aimed at addressing inequities. We need to turn from simplistic ideas encapsulated in the notion of being independent and embrace what it means to live interdependently, to take responsibility for the safety and wellbeing of not just ourselves, but others too. There is the potential for a very different way of living in, and moving about, in a community that understands interdependence. Children don't have to be delivered to the school gate to avoid the (actually very small) risk of coming to grief on neighbourhood streets. Public spaces can be shared without fear, and neighbours/citizens are clear that violence, both 'public' and 'private', is unacceptable and everybody's business. And a higher level of respect for the work of others is attained, because we share the understanding that we rely on one another for our daily living standard and wellbeing.

This is a Utopian world, you might be thinking? Well, it's never going to be a perfect world, the human animal being as it is, but we might begin to do a little better if we ditch unrealistic rhetoric about the nature of our living and help our kids to grasp a sense of their place and identity in relation to others. Perhaps it's about meaningful connectedness?

Moving on now to the content of this issue, the first paper is a captivating and thought-provoking commentary entitled 'The possum skin cloak - being warmed by culture' by Muriel Bamblett. Muriel speaks about the importance of remaining connected with culture, and she provides a beautiful analogy about the way a sense of belonging and cultural connection keeps us warm like possum skin cloaks kept our ancestors warm in days gone by. One of ways the Victorian Aboriginal Child Care Agency (VACCA) supports young indigenous people who are living in out-of-home care is through their Possum Skin Cloak project. In bringing community Elders and young people together to make possum skin cloaks, young people not only learn a traditional skill, but are engaged in important conversations that nurture relationships, culture, language, pride, healing and more. Families are invited to attend the workshops as a way of promoting a collective healing that extends beyond the young person and into family life.

Pamela Schulz, an expert in discourse analysis with a strong interest in family law and children's issues, has provided us with an account of a worrying situation in which a mother and children were potentially disadvantaged in the long term. The case before the Family Court concerned two sisters aged 4 and 5 years who had disclosed incest to a number of people, including police, their mother, maternal grandmother and 12 other people, including contact supervisors and a psychologist. While Courts request relevant experts to provide reports in order to decide what action will be in the 'best interests' of children, this article uses discourse analysis to demonstrate how mindsets of professional staff can impact upon Court decisions and outcomes for children and their parents. Pamela suggests that judges may not be receiving appropriate and comprehensive information, and need to become more aware of other issues at play within interlocutory situations that may, in fact, determine a child's wellbeing more than is currently evident before the bench.

Lesley-Anne Ey adds to the growing argument that certain aspects of popular culture contribute to unhealthy childhood development. She presents an interesting study about the ways sexualised gender stereotyping in music videos impacts on children's attitudes toward sexualised clothing attire and ultimately their gender identities. Ey argues that contemporary music media that portray women in sexualised ways have a negative influence on the way children shape their gender roles and identities. She believes that unhealthy attitudes about gender and sexualisation should be stemmed in childhood to prevent unhealthy attitudes becoming entrenched in the teenage and early adult years.

In recognition that continuity of care and connection with significant others is important for the healthy development of young people in out-of-home care, Clare Tilbury and Jennifer Osmond examined the nature of these concepts as part of pre-placement planning procedures. They point out the importance of not only considering the continuity that comes from being placed with the same families in situations of multiple placements, or maintaining connections with loved ones, but to think broadly about schools, friends, pets, toys, after-school activities, spiritual needs and so on. The authors say that out-of-home care services can be enhanced with even greater consideration of the details that help keep children connected with their community and things that are important to them.

Rudy Gonzalez and Pauline McLoughlin share the ruminations of young people who spent some of their adolescence in therapeutic residential care provided by the Lighthouse Foundation. They discuss the benefits of the specialised trauma-informed care for young people experiencing complex needs; and the way in which carers try to model and promote positive development, relationships and wellbeing for young people engaged in the service.

Sora Park talked with young people who are considered infrequent users of digital technologies, to gain a better understanding about their attitudes towards digital technology and the reasons for their infrequent use. She found that infrequent users were more likely to focus on only a small number of devices and applications, were less confident in their abilities to use the applications, and were not particularly interested in digital technologies. They did not think that digital technologies were relevant to them or their selected vocational pathways, which reinforced their lack of interest. Sora says more could be done to promote these technologies and enhance motivation, skills and perceived benefits for those young people who are less inclined to use them. 
The final paper, by Rachael Sanders, Jennifer Lehmann and Fiona Gardner, presents preliminary findings of a project that examined parents' experiences of early parenthood and their engagement with parenting information. Based on interest in how parents learn and apply important knowledge about child development and parenting practices that promote positive childhood outcomes, Rachael Sanders spoke with a number of parents about their early experiences and the ways in which they engaged with resources. Their stories reveal that early parenthood is not only a time of happiness, but also a difficult and lonely period imbued with self-doubt, exhaustion and disbelief.

This issue ends with a book review of David Tobis' book Pariahs to partners, by Charles Pragnell.

Finally, we would like to draw your attention to some special issues coming up at the end of this year and beginning of next year. In collaboration with the Lighthouse Foundation we are pleased to be able to bring you a collection of papers from their 2013 'Journey to Recovery' Conference. Continuing with the theme of childhood trauma, the March 2015 issue will be packed with papers from the Keynote speakers of the Australian Childhood Foundation International Conference - Childhood Trauma: Understanding the basis of change and recovery, and June 2015 will contain a select group of papers by some of the other presenters at that conference.

\section{References}

Kenny, M. (2014, 4 February). Hockey calls end to 'age of entitlement'. The Sydney Morning Herald. Retrieved from http://www.smh.com.au/federal-politics/political-news/ hockey-calls-end-to-age-of-entitlement-20140203-31xgl. html\#ixzz2zy3nL8Lz

Mendes, P., \& Moslehuddin, B. (2006). From dependence to interdependence: Towards better outcomes for young people leaving state care. Child Abuse Review, 15, 110-126.

Osborn, A., \& Bromfield, L. (2007). Young people leaving care. Research Brief. Canberra: National Child Protection Clearinghouse, Australian Institute for Family Studies. Retrieved from http://www.aifs.gov.au/nch/pubs/brief/rb7/rb7.pdf 